DOI: $10.30680 /$ ECO0131-7652-2018-5-81-92

\title{
Коренные малочисленные народы и добывающие компании на Обском Севере: сотрудничество или конфликт? ${ }^{1}$
}

\author{
E.A. ЕРОХИНА, доктор философских наук, Институт философии и права \\ СО РАН, Новосибирский государственный университет экономики \\ и управления, Новосибирск. E-mail: leroh@mail.ru
}

В статье рассматриваются основные источники противоречий в отношениях между общинами коренных народов и хозяйствующими субъектами в Югре. На основе анализа отдельных кейсов делается вывод о вовлечении в процессы конфликтогенеза новых акторов в лице общественных объединений и неправительственных организаций. Делаются выводы о необходимости расширения практик социального партнерства для разрешения противоречий, о значимой роли этнологической экспертизы в урегулировании конфликтов.

Ключевые слова: промышленное освоение Севера, коренные малочисленные народы России, этнологическая экспертиза, конфликт, сотрудничество, Югра

Россия сегодня - один из крупнейших поставщиков энергоресурсов на мировой рынок. Характерная особенность деятельности отечественного добывающего комплекса заключается в расширении территории промышленного освоения ресурсов на Севере и в Арктике. В отечественном научном и управленческом дискурсе освоение Арктической зоны устойчиво отождествляется с промышленной добычей энергоресурсов и налаживанием инфраструктуры для их транспортировки. Такая парадигма пространственного освоения отражает видение Севера властью и бизнесом как ничьей земли, что служит источником заблуждений, в том числе и при принятии управленческих решений.

Ключевым элементом данной парадигмы является объектное отношение к пространству как к территории, положенной на карту. Характеристикой пространства в таком понимании оказывается способность ландшафта подвергаться двумерному исчислению, а сам процесс его освоения мыслится как

\footnotetext{
${ }^{1}$ Работа выполнена в рамках раздела «Этнокультурные механизмы пространственного развития Сибири» междисциплинарного проекта «Экономико-географические, этнокультурные и историко-демографические механизмы пространственного развития Сибири» Комплексной программы фундаментальных научных исследований СО РАН II.1.
} 
инвестиционный проект, который в перспективе должен принести коммерческую выгоду. Пространство в таком понимании не обладает самоценностью для тех, кто приступает к его освоению. Между тем, как показывает исторический опыт, такой подход отнюдь не является единственно возможным. Отношение к пространству как к вмещающему ландшафту, источнику жизни и ценностному основанию собственной идентичности - это важная часть мировоззрения коренных народов Севера, связанных с ним своим образом жизни. Необходимо отметить, что вопрос о землях, территориях и ресурсах имеет приоритетное значение для коренных народов и их видения устойчивого развития. Он является одной из ежегодных тем сессий Постоянного форума по вопросам коренных народов Экономического и социального совета Организации Объединенных наций ${ }^{2}$.

В докладе о работе совещания по теме «Устойчивое развитие на территориях коренных народов» международная группа экспертов, заседавшая в Нью-Йорке 23-25 января 2018 г., указала на то, что во всем мире традиционные источники средств существования коренных народов находятся под угрозой. Как отметил в ходе совещания Э. Ларсен, угрозы для оленеводства, рыболовства и землепользования в Арктике связаны с изменениями климата, которые происходят быстрее и выражены в большей степени, чем в других регионах мира. Он также добавил, что территории коренных народов подвергаются посягательствам в ходе добычи природных ресурсов, реализации крупномасштабных проектов в области сельского хозяйства и инфраструктуры, создания природных охраняемых территорий и осуществления деятельности в сфере туризма ${ }^{3}$.

Вышесказанное можно отнести ко всем государствам, экономика которых в той или иной мере зависит от ресурсной ренты. Альтернативные подходы к пониманию роли пространства как среды для жизни и поля для проявления активности человека отчасти дополняют, а в чем-то противоречат друг другу в практиках хозяйственного освоения Обского Севера, частью которого

\footnotetext{
2 Доклад, подготовленный по итогам совещания международной группы экспертов по теме «Устойчивое развитие на территориях коренных народов» // Постоянный форум по вопросам коренных народов. Экономический и социальный совет ООН. 23-25 января 2018 г., Нью-Йорк. URL: http://undocs.org/ru/E/C.19/2018/7 (дата обращения: 10.04.2018).

${ }^{3}$ Там же.
} 
является территория современного Ханты-Мансийского округа - Югры. Взаимосвязанные и взаимоисключающие практики хозяйствования на Севере создают предпосылки как для сотрудничества, так и конфликтов в отношениях между общинами коренных малочисленных народов и добывающими компаниями в этом регионе.

\section{Между силой права и правом сильного}

В России «наступление» нефтедобывающих компаний на хрупкую природу северных территорий существенно влияет на образ жизни и практики природопользования ее граждан из числа коренных малочисленных народов. Помимо реального ущерба окружающей среде, наносимого порывами газопроводов, нефтяными разливами, разрушением шлаковых амбаров, выбросами вредных веществ в атмосферу, загрязнением рыбных нерестилищ, подрывом кормовой базы оленеводства, стоит сказать и об иных, не менее серьезных трудностях, порожденных соседством с хозяйствующими субъектами. Это, во-первых, ограничение доступа к родовым территориям через систему контрольно-пропускных пунктов, ограничивающих въезд посторонних на лицензионные участки компаний, во-вторых, нарушение сложившейся структуры родового землепользования вследствие размещения концессионных участков на землях, которые являются общинной собственностью, или в непосредственной близости от них, в-третьих, разрывы традиционных маршрутов движения людей и животных магистральными газопроводами и нефтепроводами, автомобильными и железными дорогами.

РФ как субъект международного права имеет юридические обязательства в сфере защиты интересов и поддержки коренных народов. Хотя Россия не ратифицировала Конвенцию Международной организации труда № 169 «О коренных народах, ведущих племенной образ жизни в независимых странах», принятую в Женеве на 76-й сессии Генеральной конференции MOT в 1989 г., тем не менее Конституция РФ содержит правовые нормы, отражающие наиболее существенные положения данной конвенции. В 1998 г. РФ ратифицировала Рамочную конвенцию Совета Европы о защите прав национальных меньшинств.

В соответствии с федеральным законом «О гарантиях прав коренных малочисленных народов Севера, Сибири и Дальнего 
Востока РФ» (1999 г.) все организации, ведущие хозяйственную или иную деятельность на территориях общин, занимающихся традиционными промыслами, обязаны производить оценку рисков возможного ущерба, связанного с последствиями реализации проектов, и корректировать негативное воздействие на окружающую среду и благополучие населения. Процедура оценки предполагает осуществление этнологической экспертизы - научного исследования, цель которого - выявление изменений исконной среды обитания малочисленных народов и социально-культурной ситуации их развития ${ }^{4}$.

Хотя понятие этнологической экспертизы в правовом поле существует уже достаточно долго, до настоящего времени не выработано единой, утвержденной на уровне закона надежной методики оценки ущерба, наносимого хозяйствующими субъектами общинам коренных малочисленных народов. Попытки создать такой закон неоднократно повторялись на протяжении последних двадцати лет. Но на уровне субъектов РФ законодательные акты об этнологической экспертизе стали реальным правовым инструментом лишь в Якутии - единственном регионе РФ, где такая экспертиза обязательна, ведется реестр недропользователей, работающих в местах проживания коренных народов, осуществляется контроль за их деятельностью. Что касается других субъектов РФ, то там этнологическая экспертиза не стала реальным регулятором отношений между сообществами коренных малочисленных народов и хозяйствующими субъектами.

Одна из причин такого положения - наличие на федеральном уровне довольно сильного промышленного лобби ресурсодобывающих кампаний, которые препятствуют правовым новациям, принимающим во внимание реальный, а не формальный учет ущерба. Так, в 2015 г. на обсуждение Государственной думы был внесен проект федерального закона РФ «О государственной поддержке лиц, относящихся к коренным малочисленным народам Севера, Сибири и Дальнего Востока Российской Федерации,

\footnotetext{
${ }^{4}$ Федеральный закон от 30.04.1999 № 82-Ф3 (ред. от 13.07.2015) «О гарантиях прав коренных малочисленных народов Российской Федерации». URL: http://legalacts.ru/doc/ federalnyi-zakon-ot-30041999-n-82-fz-o/ (дата обращения: 10.04.2018).
} 
ведущих кочевой и (или) полукочевой образ жизни» ${ }^{5}$. Однако в 2016 г. было принято решение о нецелесообразности данного закона. В заключении на проект от 21 марта 2016 г. отмечалось, что предложенные в законопроекте определения понятий «лица, ведущие кочевой образ жизни малочисленных народов», «места кочевий» требуют уточнения и конкретизации, поскольку не обеспечивают однозначной их идентификации. Критики законопроекта указали также на наличие в нем норм, дублирующих федеральные законы и иные нормативные правовые акты. Из-за данных замечаний законопроект не был поддержан 6 .

22 февраля 2018 г. на обсуждение был вынесен проект федерального закона об этнологической экспертизе, в котором последняя была определена как «оценка социально-культурных последствий внедряемой хозяйственной деятельности и иных управленческих решений на объекты этнокультурного наследия граждан РФ». Однако с такой концепцией выразила несогласие Ассоциация коренных малочисленных народов Севера, Сибири и Дальнего Востока РФ (КМНС). По мнению экспертов ассоциации, авторы инициативы, предлагая оценивать влияние хозяйственной деятельности на этнокультурное и нематериальное культурное наследие, игнорируют ее воздействие на исконную среду обитания, традиционный образ жизни и традиционное природопользование коренных народов ${ }^{7}$. Слушания по проекту федерального закона об этнологической экспертизе состоялись в Общественной палате РФ 21 марта 2018 г. Документ не прошел даже так называемого «нулевого» чтения - было принято решение о необходимости значительно доработать его текст, прежде чем выносить на новое обсуждение. В качестве компромиссного шага

5 Законопроект № 1026256-6 «О государственной поддержке лиц, относящихся к коренным малочисленным народам Севера, Сибири и Дальнего Востока Российской Федерации, ведущих кочевой образ жизни». URL: http://sozd.parlament.gov.ru/bill/1026256-6 (дата обращения: 10.04.2018).

6 Заключение Правительства РФ от 21 марта 2016 г. № 1777П-П44 на проект Федерального закона «О государственной поддержке лиц, относящихся к коренным малочисленным народам Севера, Сибири и Дальнего Востока Российской Федерации, ведущих кочевой образ жизни». URL: http://base.garant.ru/57727070/ (дата обращения: 10.04.2018).

${ }^{7}$ Ассоциация коренных народов Севера выступила против проекта закона об этнологической экспертизе // Национальный акцент. 2018. 22 марта. URL: http://nazaccent.ru/content/26840-associaciya-korennyh-narodov-severa-vystupila-protiv. html (дата обращения: 10.04.2018). 
Комитетом Государственной думы по делам национальностей было принято решение поддержать инициативу разработки законопроекта о сохранении и развитии нематериального культурного наследия народов России ${ }^{8}$.

В отношении же оценки современного состояния исконной среды обитания коренных народов и возможности сохранять ее как источник воспроизводства традиционного образа жизни было принято решение внести необходимые поправки в закон «О гарантиях прав коренных малочисленных народов РФ». По сообщению издания «Национальный акцент», 27 марта 2018 г. Госдума рассмотрела законопроект о компенсациях коренным малочисленным народам за ущерб, нанесенный их среде обитания хозяйственной деятельностью. Согласно законопроекту российское Правительство должно будет установить порядок и методику возмещения убытков, причиненных малочисленным народам. Документ представил заместитель руководителя Федерального агентства по делам национальностей П. Семенов, содокладчиком выступил председатель Комитета ГД по делам национальностей И. Гильмутдинов. По мнению последнего, «самое пристальное внимание» нужно уделить методике исчисления убытков, которую представят разработчики законопроекта. Он отметил, что без широкого ее обсуждения законопроект во втором чтении принят не будет ${ }^{9}$.

Таким образом, интрига сохраняется. Ее суть заключается в максимально возможном сближении нормативной базы, учитывающей интересы коренных народов, и практики правоприменения законов в отношении их реальной защиты. Если этот процесс будет тормозиться, окажется нереальным социальное партнерство в отношениях между коренными народами и добывающими компаниями. Сами практики такого партнерства ограничиваются выделением средств на строительство объектов социальной инфраструктуры, оплату путевок в санатории или детские лагеря и т.п. Эти меры, безусловно, необходимы, но не достаточны для

\footnotetext{
${ }^{8}$ В России может появиться закон о сохранении нематериального наследия коренных народов // Парламентская газета. 2018. 23 марта. URL: https://www.pnp.ru/culture/v-rossiimozhet-poyavitsya-zakon-o-sokhranenii-nematerialnogo-naslediya-korennykh-narodov.html. (дата обращения: 10.04.2018).

${ }^{9}$ Госдума рассмотрела законопроект о компенсации ущерба коренным малочисленным народам // Национальный акцент. 2018. 28 марта. URL: http://nazaccent.ru/content/26884gosduma-rassmotrela-zakonoproekt-o-kompensacii-usherba.html (дата обращения: 10.04.2018).
} 
выстраивания долгосрочной стратегии освоения Севера, создания комфортных условий жизни северян, устойчивого развития местных и региональных сообществ.

\section{Настоящее vs будущее: конфликт интересов и ценностей}

Неурегулированность правовых отношений является одной из причин конфликтогенеза вокруг территорий традиционного природопользования в Югре. Специфика данного региона - его сырьевая специализация, через которую Россия включается в международные экономические процессы. Другой характерной особенностью округа является сравнительно высокий уровень жизни, наличие рабочих мест, что служит причиной миграции этнически разнородного населения, в том числе из регионов Кавказа и Средней Азии. Это обстоятельство нередко становится источником межэтнического напряжения, чаще всего между различными этническими кланами приезжих. Однако время от времени в межэтнические конфликты втягивается и местное население: представители коренных малочисленных народов Севера и русские старожилы Югры.

По данным Всероссийской переписи 2010 г., доля хантов в структуре населения округа составляла 1,2\% (около 20 тыс. чел.), манси - 0,7\% (11 тыс. чел), ненцев - 0,1\% (1,5 тыс. чел.), коми и коми-пермяков - 0,4\% (по 2,5 тыс. чел.). Но, несмотря на, казалось бы, незначительную долю коренных малочисленных народов в этнической структуре населения региона, не превышающую $2,5 \%$ от общей численности ${ }^{10}$, реально в традиционные промыслы включена значительно большая часть сельского населения округа, проживающего преимущественно в национально-смешанных поселениях ХМАО. Высокая доля межэтнических браков, значительный процент лиц с двойной идентичностью позволяют говорить о сложившихся в округе локальных межэтнических сообществах. Важно отметить, что ядро межэтнических сообществ составляет старожильческое население: русские и представители северных этносов. Субъектность местных сообществ наиболее высока на муниципальном уровне

\footnotetext{
${ }^{10}$ Информационные материалы об окончательных итогах Всероссийской переписи населения 2010 года. Национальный состав населения по субъектам PФ.URL: http://www. gks.ru/free_doc/new_site/population/demo/per-itog/tab7 (дата обращения: 10.04.2018).
} 
и снижается по мере приближения к региональному уровню принятия решений. Однако и на этом уровне есть влиятельные общественные субъекты, в том числе организации, представляющие интересы коренных народов Севера, например, Ассоциация «Спасение Югры».

В основе конфликтов общин коренных малочисленных народов Севера и хозяйствующих на территории муниципальных образований национально-смешанных поселений Югры субъектов лежит два комплекса причин: конфликт интересов и конфликт ценностей, фундированных в представлениях о месте коренных народов в современной цивилизации. Хотя общепризнанным является взгляд на образ жизни коренных народов как элемент культурного разнообразия современного мира, не ушли в прошлое представления о них как о «дикарях» и «отсталых народах», которые препятствуют развитию в целом, в частности, национальному $^{11}$. Проиллюстрируем данный тезис на примере двух кейсов, в каждом из которых находит отражение один из двух упомянутых аспектов конфликтогенеза.

Первый из них имеет начальным эпизодом конфликт между представителем местного сообщества сельского поселения Русскинская Сургутского района ХМАО и сотрудниками ОАО «Сургутнефтегаз» осенью 2014 г. Конфликт широко известен благодаря социальным сетям, которые подробно освещали обстоятельства столкновения оленевода С. Кечимова, хранителя священного озера Имлор, с представителями «Сургутнефтегаза». Поводом стало заявление в правоохранительные органы со стороны сотрудников «Сургутнефтегаза» о покушении оленевода на убийство и расстреле двух собак, принадлежавших заявителям. На территории концессионного участка, часть которого находится в непосредственной близости от достопримечательного места, запрещены провоз домашних питомцев, а также охота и рыбалка для всех, кроме членов общины ТтП (территории традиционного природопользования), где произошли описываемые события. Нефтяники не только охотились там, где это запрещено, но и провезли собак, которые напали на оленей. Кечимов действительно угрожал им, предупреждая, что если закон против их самоуправства бессилен, то он готов защищать свое стадо и территорию самочинно. Он подписал признательные показания, хотя его адвокаты впоследствии установили, что они были получены нелегитимным способом.

Конфликт и последовавший за ним судебный процесс над Кечимовым стали предметом пристального внимания в местных сообществах, на региональном и даже международном уровне благодаря деятельности общественных организаций. В результате его освещения в СМИ и на сайтах Центрального совета коренных малочисленных народов Севера, Гринпис России, творческих организаций и организаций финно-угорского мира власть, в том числе региональная, было вынуждена прислушаться к мнению представителей местных сообществ.

\footnotetext{
${ }^{11}$ Доклад, подготовленный по итогам совещания международной группы экспертов по теме «Устойчивое развитие на территориях коренных народов» // Постоянный форум по вопросам коренных народов. Экономический и социальный совет ООН.23-25 января 2018 г., Нью-Йорк. URL: http://undocs.org/ru/E/C.19/2018/7(дата обращения: 10.04.2018).
} 
В числе результатов, достигнутых совместными усилиями, - не только «мягкий» приговор Кечимову, но и присвоение оз. Имлор статуса достопримечательного места федерального значения ${ }^{12}$.

Судебный процесс, продолжавшийся два года, завершился 2 февраля 2017 г. признанием Кечимова виновным по обоим эпизодам. Но амнистия, объявленная в апреле 2015 г. в связи с 70-летием Победы в Великой Отечественной войне, освободила его и от судимости, и от наказания в виде 300 часов обязательных работ.

Другой кейс иллюстрирует, скорее, конфликт ценностных представлений, природа которых не исключает, однако, и правовых последствий. Так, по сообщениям Ассоциации коренных малочисленных народов Севера России от 20 февраля 2018 г., в Югре участились случаи необоснованного возбуждения уголовных дел в отношении коренных народов по факту применения ими огнестрельного оружия и современных технических средств. В конце марта 2017 г. в целях самообороны четверо оленеводов из Сургутского района ХМАО вынужденно уничтожили медведицу, которая напала на ребенка одного из них. По факту охоты было возбуждено уголовное дело, изъято оружие участников охоты. Основанием для вышеуказанных мероприятий со стороны правоохранителей Югры стала такая интерпретация закона, согласно которой обеспечение традиционного образа жизни не предусматривает использования коренными малочисленными народами механических транспортных средств (снегоходов) для охоты. Следуя ей, коренные жители Севера не имеют права использовать средства современной цивилизации для ведения традиционных промыслов, в том числе охотиться на медведя. Однако, как утверждает эксперт в области прав коренных народов Ю. Якель, такого запрета в законодательстве Российской Федерации нет ${ }^{13}$.

В обращении к Генеральному прокурору РФ с просьбой восстановить справедливость и снять незаконные обвинения эксперт обратила внимание на противоречие между законодательными нормами и правоприменительной практикой. Однако данный случай показателен еще и тем, что иллюстрирует существующие в обыденном сознании мифы о традиционном образе жизни как жизни в чуме, без доступа к современным технологиям, средствам охоты и связи.

Сегодня глобальная коммуникация дает локальным сообществам Обского Севера больше возможностей для донесения своей позиции не только власти, но и широкой общественности. Так,

12 Оставить священное озеро без хранителя? В Югре разгорается скандал вокруг культового места аборигенов // URAnews. 2015. 17 июня. URL: https:/ura. news/news/1052211947; Один на озере нефти // Радио Свобода. 2015. 21 августа.URL: https://www.svoboda.org/a/27199956.html; Cmепьгин A. ООН вмешалась в спор аборигенов Югры с «Сургутнефтегазом» // URAnews. 2015. 6 октября. URL: https://ura.news/ articles/1036272527; Дело Кечимова близится к развязке //Surgutfilm.. 2016.9 декабря URL: http://surgutfilm.ru/delo_kechimova; Югорскому шаману Кечимову вынесли приговор //Национальный акцент. 2017. 3 февраля. URL: http://nazaccent.ru/content/23073yugorskomu-shamanu-kechimovu-vynesli-prigovor.html. (дата обращения: 10.04.2018).

13 Якель Ю. Без вины виноватые. Традиции и закон - две грани жизни коренных малочисленных народов. 20.02.2018. URL: http://raipon.info/info/news/3018/ (дата обращения: 10.04.2018.) 
благодаря социальным сетям инциденты, связанные с ущемлением прав коренных народов Севера, быстро попадают на новостные ленты и становятся предметом общественного обсуждения.

Определенный прогресс в отношении прав аборигенов на землю наметился еще в 1990-е гг. [Попков,1998. С.141; Мархинин, Удалова, 2002]. Тем не менее идея корпоративной социальной ответственности еще не стала определяющей в деятельности естественных монополистов - крупных хозяйствующих субъектов [Новикова, 2016. С. 133]. Государство предпринимает определенные меры для того, чтобы побудить компании выстраивать систему долгосрочных партнерских отношений со старожильческим населением, в том числе и через разработку законодательных инициатив. Однако отсутствие реальных правовых механизмов, позволяющих учитывать наносимый территориям традиционного природопользования ущерб и заставляющих компенсировать его размер общинам коренных малочисленных народов, по факту не позволяет ограничивать произвол компаний.

Проблема социального благополучия жителей региона, в том числе и обладающих особыми, коллективными правами, изучалась сотрудниками Института философии и права СО РАН в ходе экспедиции в Ханты-Мансийский автономный округ в 2014 г. Одна из задач исследования заключалась в выявлении показателей социального самочувствия членов межэтнических сообществ Обского Севера: степени удовлетворенности различными сторонами жизни; ожиданий от будущего; восприятия своей идентичности. Всего было опрошено 442 жителя региона, в том числе 71 представитель коренных малочисленных народов. На вопрос анкеты массового опроса «Каким Вы видите будущее коренных малочисленных народов Севера России?» были получены ответы 149 респондентов (таблица).

Обращает на себя внимание тот факт, что представления о будущем коренных малочисленных народов ХМАО различаются у их представителей (хантов и манси) и у других этносов (русских, украинцев, выходцев из регионов Кавказа и Средней Азии и др.). Так, почти половина опрошенных из числа представителей некоренных этносов уверены, что будущему развитию коренных малочисленных народов ничего не угрожает, в то время как большинство хантов и манси солидарны с 
диаметрально противоположной оценкой: 61,2\% из них считают, что их будущее находится под угрозой. В данном контексте тревожит пессимистическое видение современного состояния и перспектив своего развития представителями коренных малочисленных народов на фоне спокойного его восприятия другими опрошенными.

\section{Каким вы видите будущее коренных малочисленных народов Севера России, \%}

\begin{tabular}{|l|l|c|c|c|}
\hline \multicolumn{1}{|c|}{ Ответ } & & Другие народы & КМНС & Всего \\
\hline \multirow{2}{*}{$\begin{array}{l}\text { Я считаю, что их будущему ничто } \\
\text { не угрожает }\end{array}$} & По числу ответивших & 40 & 12 & 52 \\
\cline { 2 - 5 } & В \% по столбцу & 48,8 & 17,9 & 34,9 \\
\hline \multirow{2}{*}{$\begin{array}{l}\text { я считаю, что их будущее находится } \\
\text { под угрозой }\end{array}$} & По числу ответивших & 27,0 & 41,0 & 68,0 \\
\cline { 2 - 5 } & В \% по столбцу & 32,9 & 61,2 & 45,6 \\
\hline \multirow{2}{*}{ Другое } & По числу ответивших & 3,0 & 2,0 & 5,0 \\
\cline { 2 - 5 } & В \% по столбцу & 3,7 & 3,0 & 3,4 \\
\hline \multirow{2}{*}{ Трудно сказать } & По числу ответивших & 12,0 & 12,0 & 24,0 \\
\cline { 2 - 5 } & В \% по столбцу & 14,6 & 17,9 & 16,1 \\
\hline
\end{tabular}

При этом, отвечая на вопрос: «Довольны ли вы сейчас в целом своей жизнью», более половины респондентов из числа представителей коренных малочисленных народов дали положительный ответ $(51,5 \%)$. Сопоставление двух показателей социального самочувствия - удовлетворенности своей жизнью в настоящем и неуверенности в будущем - позволяет предположить, что на уровне повседневного горизонта бытия представители коренных малочисленных народов сохраняют устойчивую ориентацию «жить сегодняшним днем». Следовательно, и право на культурное самоопределение в определенных обстоятельствах может быть принесено в жертву сиюминутным выгодам.

Между тем сокращение численности северных этносов под воздействием хозяйственных практик доминирующего большинства может привести и к исчезновению уникальных способов взаимодействия человеческого коллектива с пространством вмещающего ландшафта, и к деградации самого ландшафта. Хотя реализация такого пессимистичного сценария вряд ли возможна, тем не менее вовсе исключать его было бы неправильно. Сама вероятность такого исхода должна маркировать предел стратегии, нацеленной на ресурсную эксплуатацию и практики экстрактивизма. Необходимо переосмысление парадигмы освоения Севера 
в новых категориях, предполагающих возможность не только экономической, но и этической его оценки.

\section{Литература}

Мархинин В.В., Удалова И.В. Традиционное хозяйство народов Севера и нефтегазовый комплекс (социологические исследования в Ханты-Мансийском автономном округе). Новосибирск: Наука, 2002. 254 с.

Новикова Н.И. Нефть, газ, коренные народы: кто напишет правила? // Вестник угроведения. 2016. № 3 (26). С. 124-137.

Попков Ю. В. Народы Севера и нефть // ЭКО. 1998. № 7. С. 137-142.

Статья поступила 10.04.2018.

\section{Summary}

Erokhina E.A., Institute of Philosophy and Law, SB RAS, Novosibirsk State University of economics and Management, Novosibirsk

Indigenous Peoples and Mining Companies in the Ob North: Cooperation or Conflict?

The article considers the main sources of contradictions in relations between indigenous communities and business entities in Ugra.Based on the individual case-studies, it is concluded that new actors such as public associations and non-government organizations are involved in the conflict genesis processes.It is concluded that it is necessary to expand a practice of social partnership to resolve contradictions, and that ethnological examination has the significant role in disputes settlement.

Industrial development of the North; indigenous small peoples of Russia; ethnological expertise; conflict; cooperation; Ugra

\section{References}

Marhinin V.V., Udalova I. V. (2002) Tradicionnoe hozjajstvo narodov Severa i neftegazovyj kompleks (sociologicheskie issledovanija v Hanty-Mansijskom avtonomnom okruge). Novosibirsk. Nauka Publ. 254 p.(In Russ.)

Novikova N.I. (2016) Neft', gaz, korennye narody: kto napishet pravila? Vestnik ugrovedenija. No. 3 (26). Pp. 124-137. (In Russ.)

Popkov Ju.V. (1998) Narody Severa i neft'. ECO. [ECO]. No. 7. Pp. 137-142. (In Russ.) 